\title{
THE IMPACT OF ELECTRIC VEHICLES ON SMART GRID
}

\author{
Daniel PÁL, Lubomír BEŇA, Maksym OLIINYK \\ Department of Electric Power Engineering, Faculty of Electrical Engineering and Informatics, \\ Technical University of Košice, Letná 9, 04200 Košice, Slovak Republic, tel. +421 55602 3566, \\ E-mail: daniel.pal@tuke.sk, lubomir.bena@tuke.sk,maksym.oliinyk@tuke.sk
}

\begin{abstract}
This publication examines the impact of electric vehicles on the grid. Electric cars are becoming more and more popular in the world. The annual sales quantity of electric cars in the world has an upward trajectory which has some serious implications on the electric grid as well. Both passenger and freight transport are being influenced by this current trend. In addition to various methods of transport, electric cars have the potential to transform traditional grids into smart ones. The primary objective of this study is to examine to what extent the voltage at the nodes changes when electric cars are connected to the network and also sets out to provide us with some overview of the effects on active power loss in the network.
\end{abstract}

Keywords: CO2 reduction, electric vehicles, power losses, SMART GRID

\section{INTRODUCTION}

Electric cars are becoming more and more popular not only in the European Union, but also in the rest of the world. Their use has the potential to reduce the amount of $\mathrm{CO} 2$ generated during transport. Moreover, this means of transport might also play an important role in changing the network itself. Once the traditional grid becomes an intelligent grid, electric cars and renewable energy sources will be essential to grid security. Their capacity can ensure energy production even if the renewable sources do not produce enough and, furthermore, they have also an important part to play in voltage regulation.

\section{SMART GRID}

The current electrical grid has evolved over many decades. Since it has already reached its peak of development, new forms of network should be introduced. As far as the traditional grid is concerned, they can no longer operate efficiently under such a changed technological environment (renewable energy, electric cars) which makes the smart grid much more desirable. This smart grid can react to problems in the network and has the capacity to fix them automatically. The development of information technology also helps to a great extent provided that the right management parameters are put in place [1], [2], [3].

The Smart Grid is shown in the Fig. 1. In addition to conventional grid power plants (nuclear power plant, thermal power plant) it also contains other elements such as renewable energy power plants, solar panels installed in households or electric cars. However, renewable energy sources have their limitations. The solar panels produce no energy during the night which clearly demonstrates that the power supply of a whole city cannot be based solely on it alone. Not to mention the fact the renewable energy sources tend to be unpredictable as they do not have the ability to generate power at a constant rate during the whole day which makes the power supply quite unpredictable. The electric vehicles battery can be storage of renewables, so there is no need for additional storage. This can eliminate the disadvantages of solar panels as they do not produce energy at night. The energy produced during the day would be stored in the batteries of the cars, which can be used at night [4].

The primary objective of the smart grid is to eliminate such shortcomings. There are two-way communication patterns in this network allowing the equipment to acknowledge what processes are taking place on the other equipment. As a result, it becomes possible to come up with any kind of solution to problems in the network under relatively short notice such as short circuits, open lines, or to increase / decrease the power of power plants in relation to consumption.

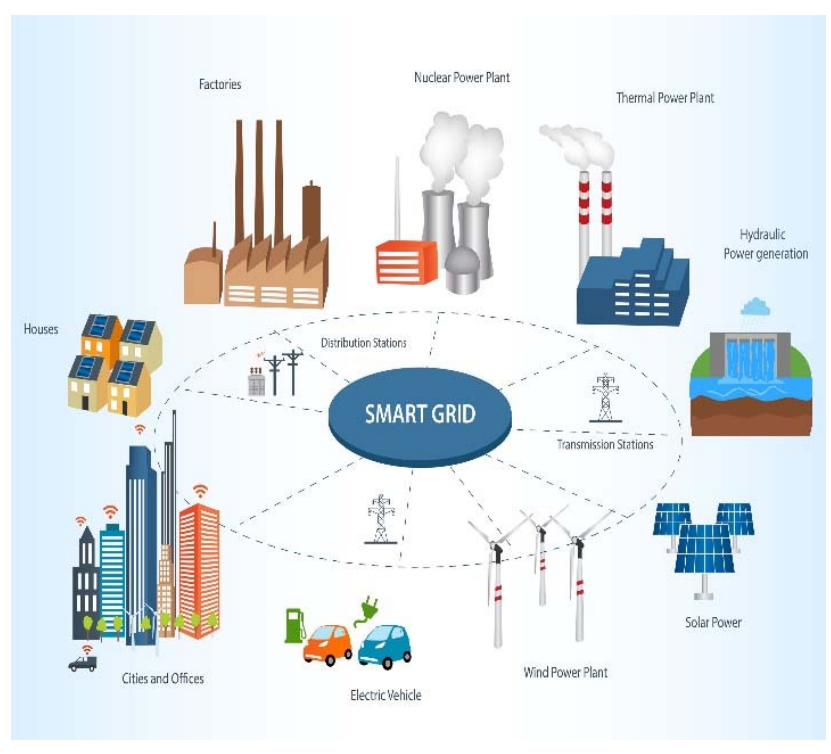

Fig. 1 SMART GRID [1]

This article focuses on the role of electric cars in the grid.

\section{ELECTRIC VEHICLES}

In recent years, the European Union (EU) has placed great emphasis on the use of renewable energy sources (RES) compared to conventional sources. The EU has made commitments to cover $20 \%$ of final energy consumption 
from RES by the end of 2020. For 2030, it will have to be increased to $32 \%$ of final consumption of RES [5], [6].

It also aims to increase energy efficiency so that more energy can be produced from the same amount. By the end of 2020 , the $20 \%$ improvement in energy efficiency would be desirable [5], [6]. This is important because of the fact that the availability of non-renewable energy sources is limited.

Moreover, the EU set to reduce greenhouse gas emission by $20 \%$ compared to 1990 [5], [6]. In the European Union, Studies suggest that various means of transport is responsible for almost $30 \%$ of $\mathrm{CO} 2$ emissions of which $72 \%$ can be attributed to road transport. Given the fact that the road traffic plays such an important role in $\mathrm{CO} 2$ production, various types of vehicles and fuels were subjected to analysis [7]. This is shown in the Fig. 2. It clearly demonstrates the fact that electric cars powered by renewable energy sources have the lowest $\mathrm{CO} 2$ emission rates. The most popular cars such as petrol and diesel driven cars are third and fourth in this ranking. The worst-case scenario presents itself when the electric car is charged with electricity generated in coal-fired power plants. As a matter of fact, it is not possible to compare these cars and fuel types based solely on $\mathrm{CO} 2$ emissions, because petrol and diesel-driven cars also emit other gases into the air while moving.

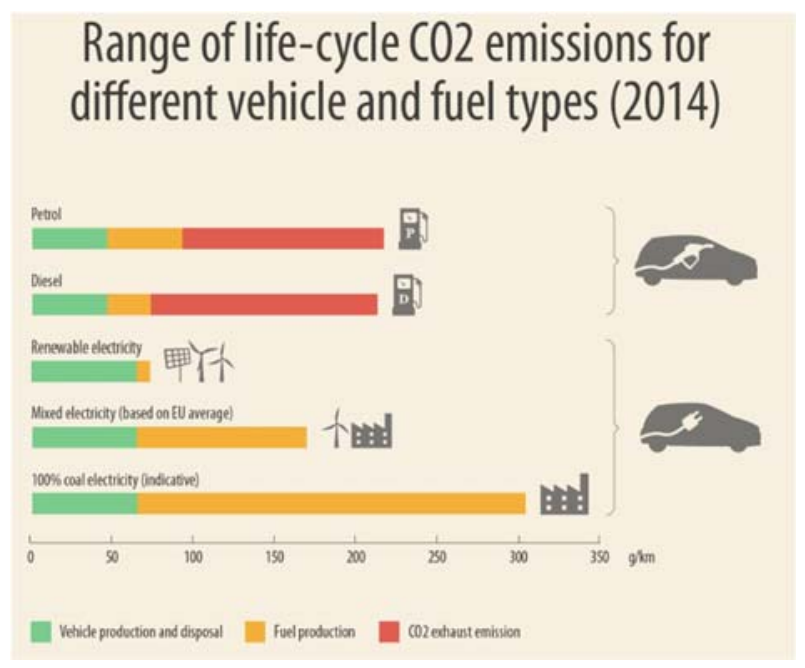

Fig. 2 Range of life-cycle $\mathrm{CO} 2$ emissions for different vehicle and fuel types [7]
Fig. 3 shows that the demand for electric cars has growing tendency. The world production of electric cars has grown seven times bigger over the last 4 years. China is the leading force in this industry with half of the production taking place over there.

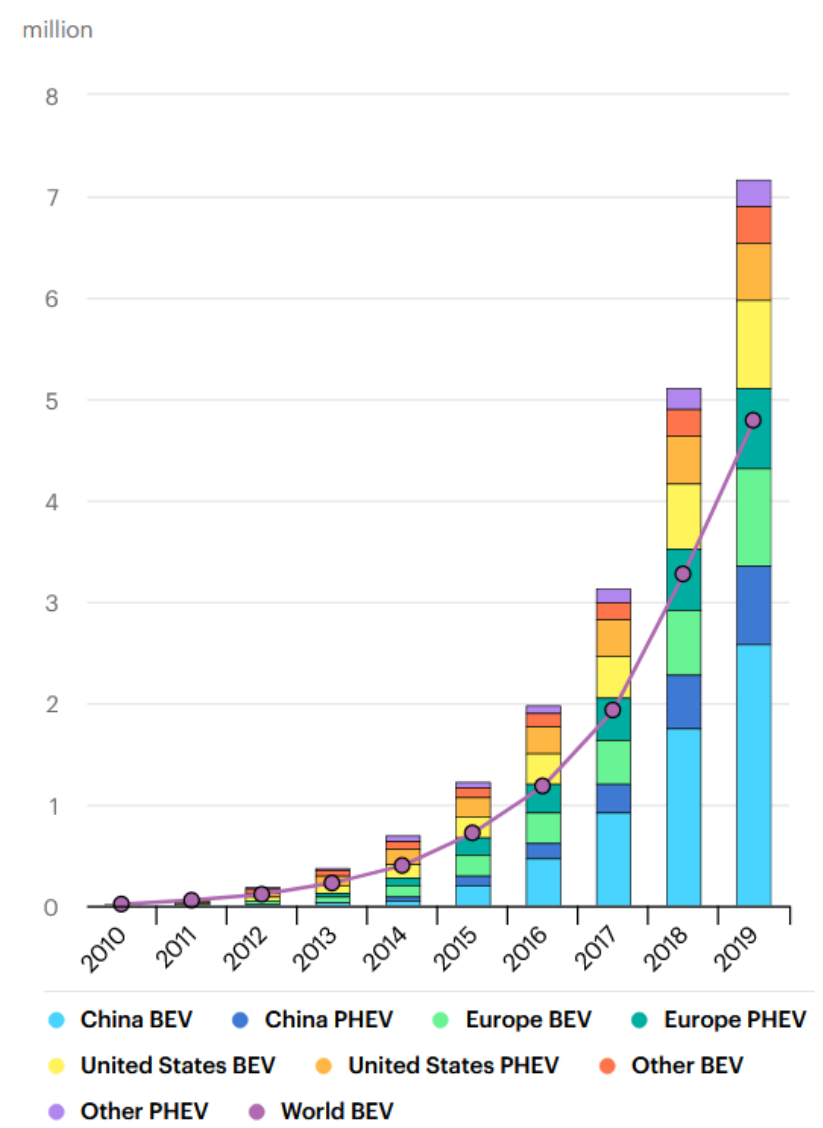

Fig. 3 Global electric car stock [8]

Fig. 4 shows the most popular electric cars of the first half of 2020. Tesla Model 3 leads the way with considerable advantage. Tesla is followed by Renault Zoe, Nissan LEAF and then Volkswagen e-Golf [9]. If we supplement Fig. 3 with these data, we conclude that there is a growing demand for electric cars which underlies their importance in the network as well. 


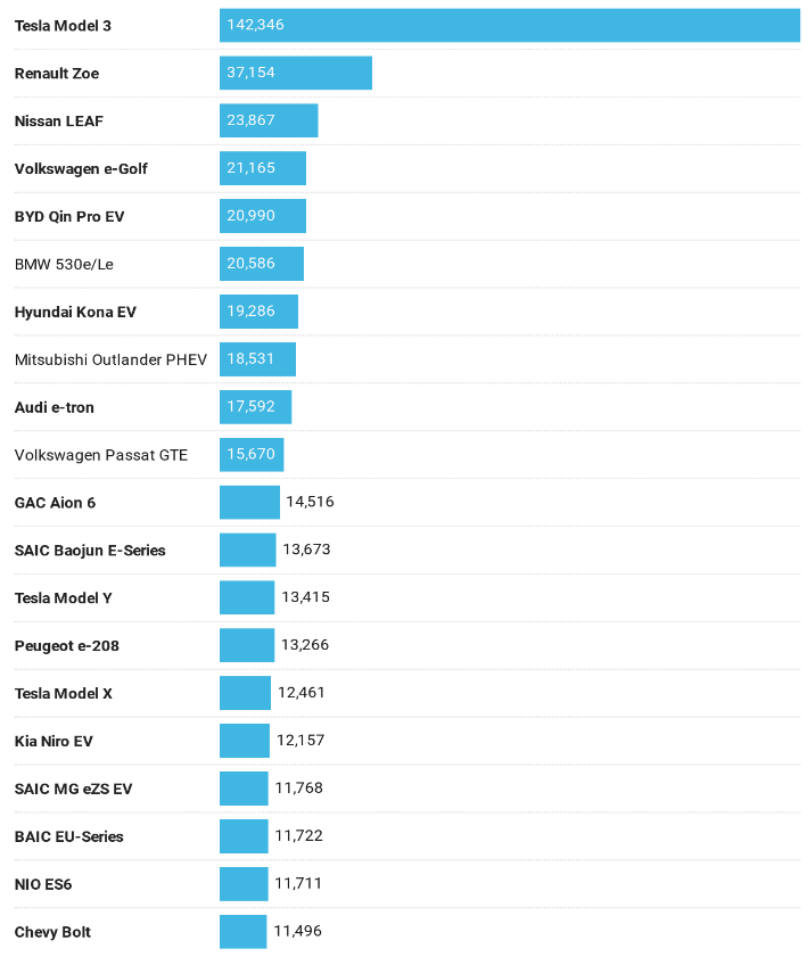

Fig. 4 Top 20 electric vehicles in World ( $1^{\text {st }}$ half of 2020) [9]

\section{SIMULATED NETWORK}

The tested network topology is shown in Fig. 5 which served as a platform for our calculations. It was investigated the effect of electric cars on the rest of the network, primarily on the loss and voltage at the nodes.

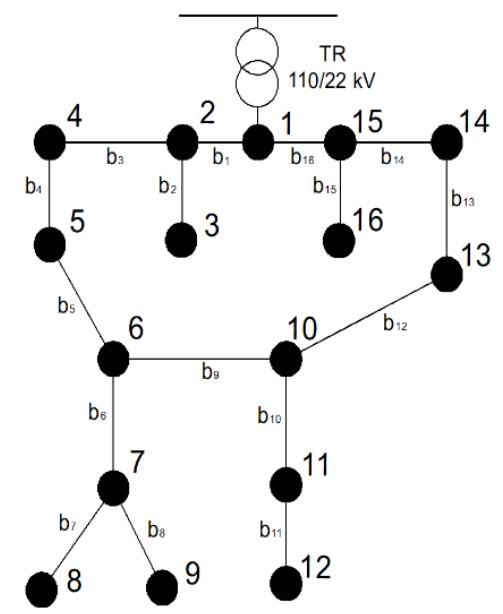

Fig. 5 Topology of the network
To calculate the network loss and node voltages from this topology, the network parameters are required. Resistance and inductive reactance were considered in the branch parameters. These values have been converted to the length of the branch, so they are not given in $\Omega / \mathrm{km}$ but in $\Omega$. I used 3 types of branches in the examined network. The values of each branches are shown in Table 1.

Table 1 Branch parameters

\begin{tabular}{ccc} 
Branch & $\begin{array}{c}\text { Resistance } \\
(\Omega)\end{array}$ & $\begin{array}{c}\text { Inductive reactance } \\
(\Omega)\end{array}$ \\
\hline \hline 1 & 0.90 & 0.99 \\
\hline 2 & 1.25 & 0.86 \\
\hline 3 & 0.90 & 0.99 \\
\hline 4 & 1.05 & 0.72 \\
\hline 5 & 1.40 & 0.97 \\
\hline 6 & 0.69 & 0.35 \\
\hline 7 & 1.24 & 0.64 \\
\hline 8 & 1.17 & 0.60 \\
\hline 9 & 0.75 & 0.52 \\
\hline 10 & 0.97 & 0.50 \\
\hline 11 & 0.90 & 0.46 \\
\hline 12 & 0.40 & 0.28 \\
\hline 13 & 0.40 & 0.28 \\
\hline 14 & 0.24 & 0.27 \\
\hline 15 & 1.05 & 0.72 \\
\hline 16 & 0.54 & 0.60
\end{tabular}

The other important input is the node parameter displayed in the Table 2. We considered two parameters which aimed to model the nodes. These were active and reactive powers. Except of 1 node, every node in the network were a consumer node. These consume power from the network.

Table 2 Node parameters

\begin{tabular}{ccc||ccc} 
Node & $\begin{array}{c}\mathrm{P} \\
\text { (MW) }\end{array}$ & $\begin{array}{c}\text { Q } \\
\text { (MVAr) }\end{array}$ & Node & $\begin{array}{c}\mathrm{P} \\
\text { (MW) }\end{array}$ & $\begin{array}{c}\text { Q } \\
\text { (MVAr) }\end{array}$ \\
\hline \hline 1 & 0 & 0 & 9 & 1.2 & 0.10 \\
\hline 2 & 1.5 & 0.20 & 10 & 0.9 & 0.05 \\
\hline 3 & 0.8 & 0.10 & 11 & 0.9 & 0.05 \\
\hline 4 & 1.4 & 0.20 & 12 & 1.2 & 0.10 \\
\hline 5 & 0.6 & 0.05 & 13 & 0.6 & 0.15 \\
\hline 6 & 0.9 & 0 & 14 & 1.4 & 0.15 \\
\hline 7 & 0.7 & 0.10 & 15 & 1.5 & 0.20 \\
\hline 8 & 1.2 & 0.05 & 16 & 0.8 & 0.05 \\
\hline
\end{tabular}


The data in Table 1 and Table 2 were entered into the program and assigned to each other using the network topology shown in the Fig. 5. This allowed the program to determine which branches connected which nodes.

The calculations were performed with software MATLAB which allows us to structure the topology of the network using the digraph function (Fig. 6). Its primary purpose is to monitor whether the program is working with the expected network or if an error has occurred in entering the data which causes a branch to be associated with another node.

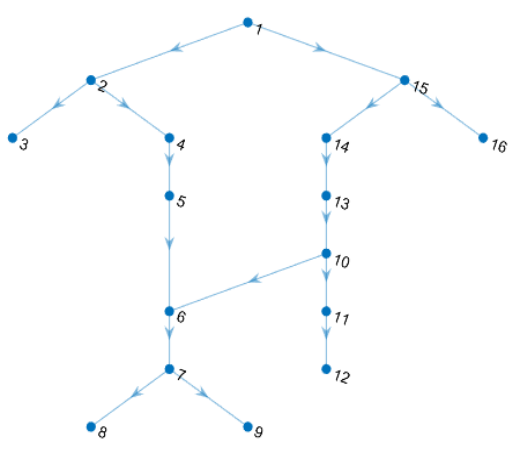

Fig. 6 Drawn topology with MATLAB software

This article examined the impact of electric cars on the grid. Electric cars are generally considered to be consumers because they consume energy from the grid when charged, but they are also able to transfer energy back into the grid. This is the V2G technology. Vehicle-to-grid (V2G) is a technology whose objective is to better integrate electric cars into the power systems, can provide EV battery energy to the grid. V2G technology offers active power regulation, voltage and frequency control [10], [11], [12], [13]. With the help of these can improve grid efficiency, stability, and reliability.

In the next section, all 2 options were examined.

All the connection points for electric cars have been marked in the topology figure (Fig. 5) for better visibility. The connection points were divided into 3 groups to represent the actual states as accurately as possible (Fig. 7). The red dots set to represent workplaces, the green ones public charging stations while the households are highlighted by blue colour. This division will play an important role in the simulation process.

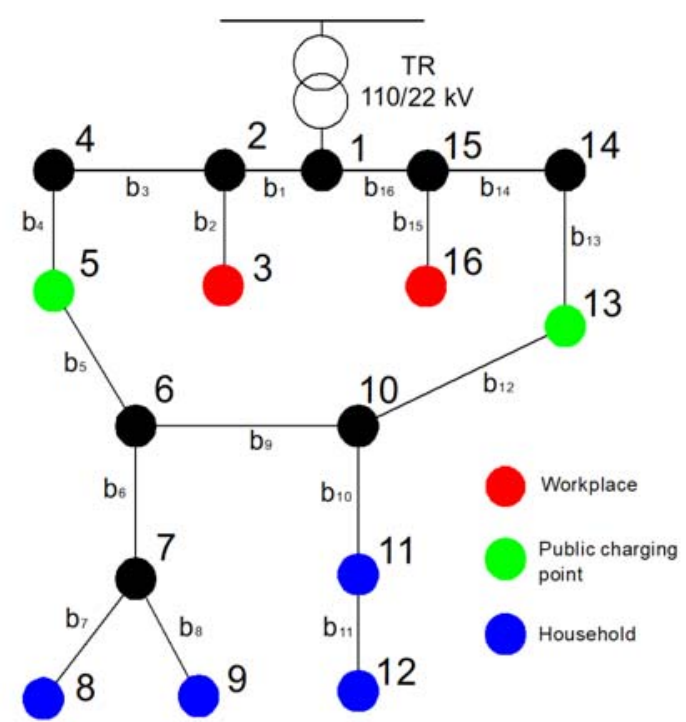

Fig. 7 Topology of the network with connection points

Electric cars cannot be connected directly to the $22 \mathrm{kV}$ voltage network. A charging station is required that is connected to $400 \mathrm{~V}$ and then $400 \mathrm{~V}$ voltage is being transformed to the $22 \mathrm{kV}$ (Fig. 8). To achieve this particular goal, the transformer with the following parameters has been used which are shown in Table 3 . The spare shortcircuit impedance of the transformer was calculated with the Table 3 .
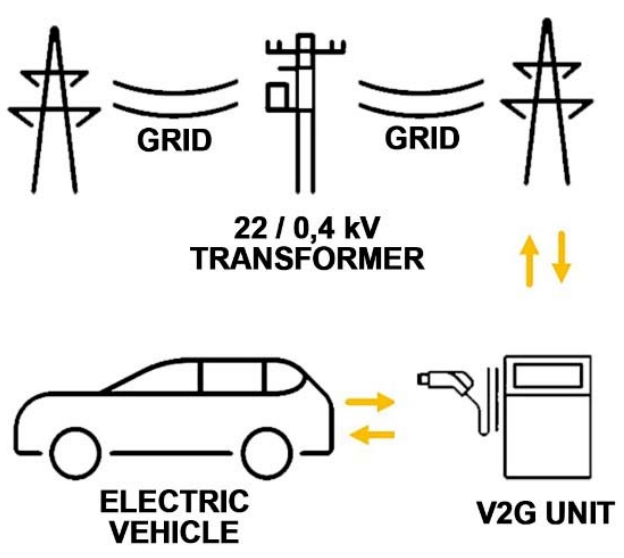

Fig. 8 Connection of electric cars [14] 
Table 3 Technical parameters of HV / LV transformer

\begin{tabular}{|l|l|}
\hline Rated power & $1 \mathrm{MVA}$ \\
\hline Rated higher voltage & $22 \mathrm{kV}$ \\
\hline Rated lower voltage & $0.45 \mathrm{kV}$ \\
\hline No-load losses & $1.7 \mathrm{~kW}$ \\
\hline Short-circuit losses & $13 \mathrm{~kW}$ \\
\hline Short-circuit voltage & $6 \%$ \\
\hline
\end{tabular}

\section{RESULTS}

The following scenarios were considered during the simulation:

- Scenario 1 - in this case, only for the selected points can be added electric vehicles. Up to 20 cars can be added to each node. A special feature of this scenario is that the number of cars increases at the same rate in selected nodes. If 4 is added to one, it increases by the same amount as the other nodes.

- Scenario 2 - the natural movement of people was simulated. In the morning, people go to work with electric vehicles.

- Scenario 3 - this case shows the lunch time, when some people go home for lunch and others stay at work.

- Scenario 4 - this case was the opposite of Scenario 2. People go home after work with electric cars.

- Scenario 5 - in the last case, it was examined what happens with the grid parameters, when the cars not only consume but also produce electricity in the grid.

\subsection{Scenario 1}

In this scenario, it was possible to add up to 20 cars to each of the selected points (nodes 3, 5, 8, 9, 11, 12, 13, 16). Each car also has a charging station. Each of these charging stations provides $50 \mathrm{~kW}$ of power. In total, these provide 1 MW each. This allowed a maximum of 160 cars to be connected to the entire network.

At the beginning of the simulation, we calculated the current state in order to compare the results. In the current state, no electric cars were connected to the selected points. After simulation of the current state, we add 4 cars to the selected points. We calculated the node voltage along with the losses. Subsequently, we added 4 more cars to the selected points. We followed this mechanism until we reached the maximum number of the cars. As far as the graph is concerned, it can be concluded that when the cars are charged and consume electricity, the voltage volume at the nodes became less and less. Whenever 4 cars were connected, the voltage decreased average by $0.2 \mathrm{kV}$ at each node. In some nodes, the voltage decreased only $0.02 \mathrm{kV}$, in others $0.15 \mathrm{kV}$. The average decreasing was $0.09-0.10$ $\mathrm{kV}$. As soon as these cars transferred electricity back to the grid, the voltage became higher (Fig. 9).

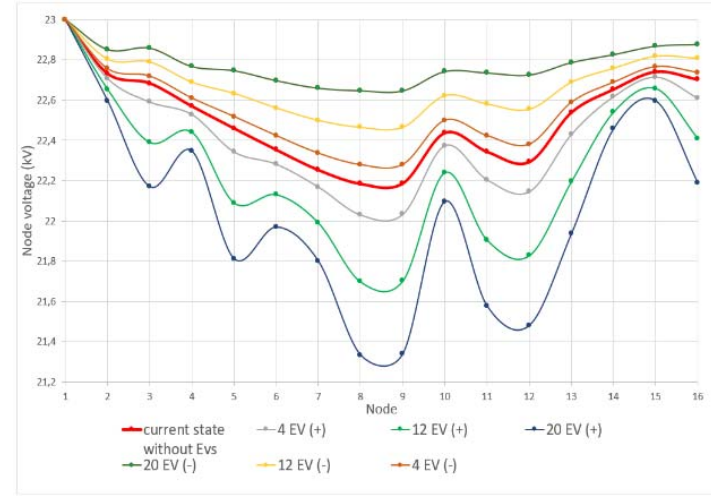

Fig. 9 Voltage distribution between the nodes based on Scenario 1

A similar phenomenon was observed in both the evaluation of the loss and voltage, shown in Fig. 10. If we charge the cars, the total losses will subsequently be increased. Provided that the cars brought electricity back into the grid, we can witness the volume of the loss decreased. The more cars connected, the greater the difference would be in relation to the total loss.

The initial active loss was $0.33 \mathrm{MW}$. This loss increased to $0.97 \mathrm{MW}$ when all 160 were added to the network. This is a $300 \%$ increase in active loss. The initial reactive loss was $0.31 \mathrm{MVAr}$. This loss increased to $1.27 \mathrm{MVAr}$ when all 160 were added to the network. This is a $400 \%$ increase in loss.

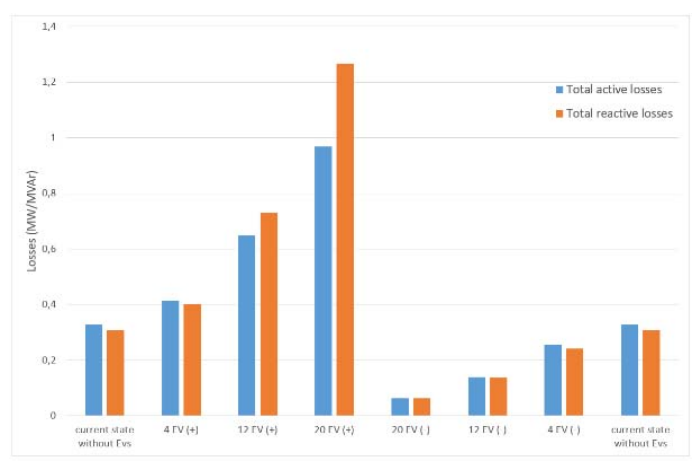

Fig. 10 The change in active and reactive losses based on Scenario 1

\subsection{Scenario 2}

Over the course of this scenario, we tried to monitor the natural way how people move when going to work. The time frame of this happening corresponds to mornings when they gradually drive to work. We tried to simulate the movement of 60 cars. These 60 cars will gradually be on the move from homes to workplaces. In addition, 5 cars were added to the public charging points.

It can be seen from the Fig. 11 that when people were at home, the voltage was lower at these nodes. Cars were charged there. As more and more people were leaving for work, the voltage started to increase, however, the situation was quite the opposite at workplaces mainly because cars had been charged predominantly over there. 


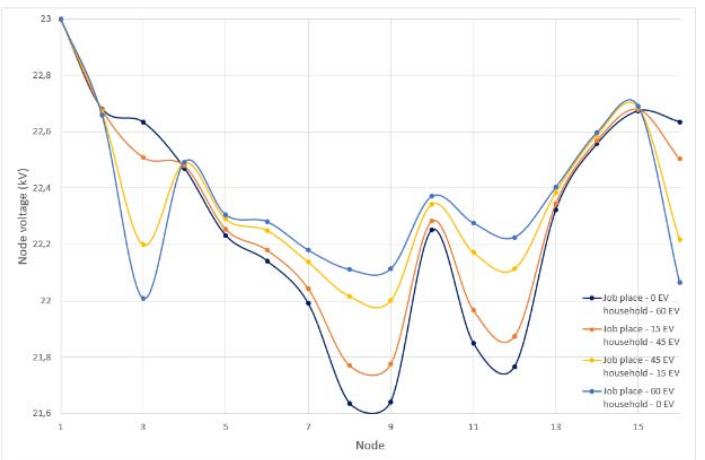

Fig. 11 Voltage distribution between the nodes based on Scenario 2

It made no difference whether people were at home or at work when it came to losses making up only for 0.11 MW and 0,12 MVAr. The loss rate was lower at the workplace due to less resistance of these branches. Shown in Fig. 12.

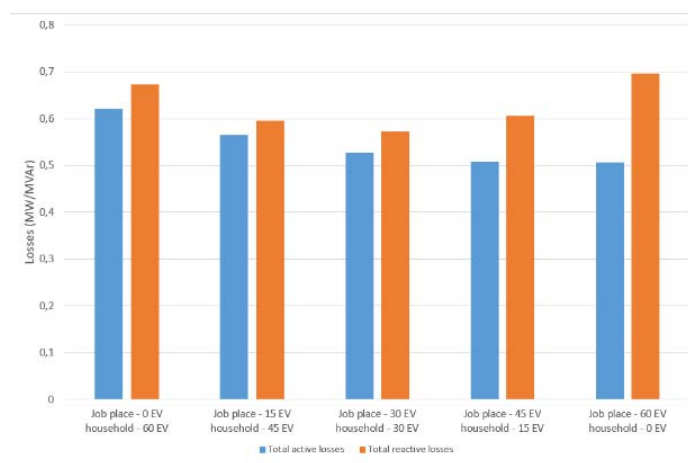

Fig. 12 The change in active and reactive losses based on Scenario 2

\subsection{Scenario 3}

In this particular case, we tried to simulate a situation around noon when people go to lunch (many of them even go home). If we took the sum of 60 cars into consideration, the half of them would remain in the work and another $50 \%$ opted for going home for lunch.

As a result (Fig. 13), the voltage rates got levelled up with the worst value being $21.9 \mathrm{kV}$, when $50 \%$ of the cars remain in the workplaces and $50 \%$ of the cars leave the workplaces. The differences would not be as great as if they had these 60 cars at work or at home, as seen in the Fig. 13.

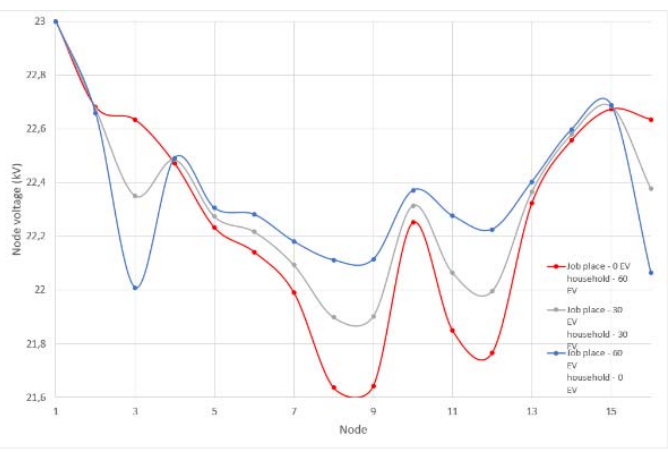

Fig. 13 Voltage distribution between the nodes based on Scenario 3

\subsection{Scenario 4}

For this particular instance, we set out to comprehend the process of coming home in the evening. This is essentially the same as Scenario 2, but the other way around. People left their workplaces and were going home. As more and more cars were leaving their workplaces, the value of voltage nodes situated at working environment had an upward trajectory while the tendency is exactly the opposite associated with home nodes.

\subsection{Scenario 5}

We have considered cars as consumers over the course of different scenarios up to this point. The only exception was Scenario 1 where cars were presented as the producers as well. By implementing V2G technology, it became possible to transfer electricity back into the electrical network in order to achieve better regulation parameters. This is one of the benefits associated with Smart Grids.

We looked at different scenarios once $0,25,50,75$ and $100 \%$ of cars generate electricity back into the grids. As more and more cars were being considered as producers, the voltage was getting increased, the value of the losses decreased. Shown in Fig. 14 and Fig. 15.

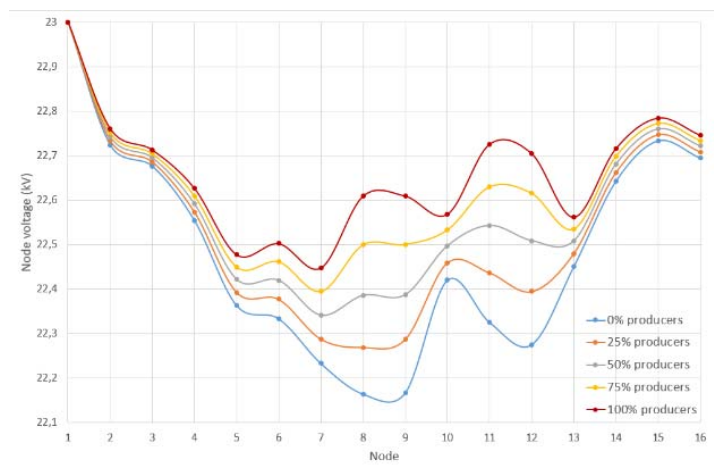

Fig. 14 Voltage distribution between the nodes based on Scenario 5

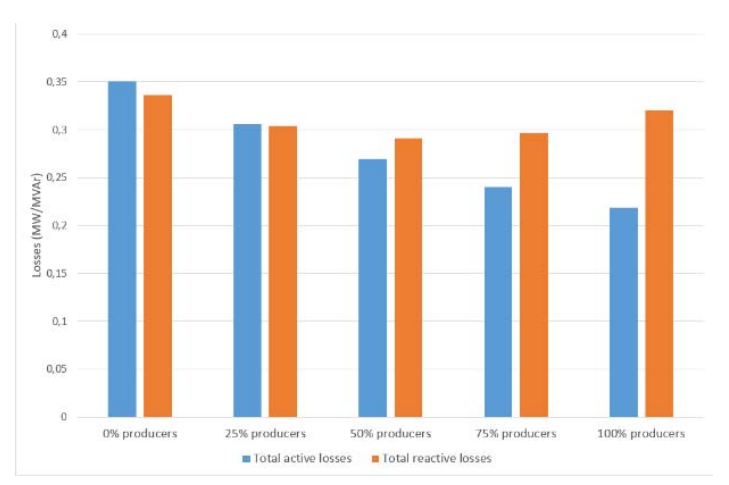

Fig. 15 The change in active and reactive losses based on Scenario 5

\section{CONCLUSIONS}

The aim of the publication was to draw attention to the possible impact of electric vehicles on mains voltage and loss. It was proved that the electric vehicles were able to increase or decrease the voltage depending on the fact 
whether we considered them as consumers or as producers. It was also seen that in addition to voltages, they are also able to influence network power losses. The decrease / increase depends also on whether we view them as consumers or as producers. As the consumption increased, the voltage at the nodes decreased (the node with the largest increase in consumption decreased the most), and when the consumption decreased, the voltage at the nodes increased. In Smart grids is the 2-way communication, which is one of the advantages of smart grids, it is possible to generate energy close to consumption which has the tendency to reduce grid power losses. In addition, it has been shown that the movement of people by electric car also influences node voltages.

\section{ACKNOWLEDGMENTS}

This work was supported by the Slovak Research and Development Agency under the contract No. APVV-190576 .

\section{REFERENCES}

[1] The Smart Grid Could Hold the Keys to Electric Vehicles [online]. Available at: $<$ https://innovationatwork.ieee.org/the-smart-gridcould-hold-the-keys-to-electric-vehicles/> Accessed on November 14, 2020.

[2] Smart grids: what is a smart electrical grid electricity networks in evolution [online]. Available at: $\quad<$ https://www.i-scoop.eu/industry-4-0/smartgrids-electrical-grid/> Accessed on November 16, 2020.

[3] The Smart Grid [online]. Available at: $<$ https://www.smartgrid.gov/the_smart_grid/smart_g rid.html $>\quad \mathrm{C}: \backslash$ Users $\backslash$ Daniel $\backslash$ Desktop $\backslash$ Acta aei $<$ https: www.smartgrid.gov $\backslash$ the_smart_grid $\backslash$ smart _grid.html $>$ Accessed on December 1, 2020.

[4] MOULI, G. R. C. - VENUGOPAL, P. - BAUER, P.: "Future of electric vehicle charging," 2017 International Symposium on Power Electronics (Ee), Novi Sad, 2017, pp. 1-7, doi: 10.1109/PEE.2017.8171657.2020. Available at: $<$ https://ieeexplore.ieee.org/document/8171657>

[5] 2020 climate \& energy package [online]. Available at: $<$ https://ec.europa.eu/clima/policies/strategies/2020 en>. Accessed on December 14, 2020.

[6] 1. Overall progress towards the European Union's '2020-20' climate and energy targets [online]. Available at:

$<$ https://www.eea.europa.eu/themes/climate/trendsand-projections-in-europe/trends-and-projections-ineurope-2017/overall-progress-towards-theeuropean $>$ Accessed on December 14, 2020

[7] $\mathrm{CO} 2$ emissions from cars: facts and figures (infographics) [online]. Available at: $<$ https://www.europarl.europa.eu/news/en/headlines/ society/20190313STO31218/co2-emissions-from- cars-facts-and-figures-infographics $>$ Accessed on December 15, 2020.

[8] Global EV Outlook 2020. Entering the decade of electric drive [online]. Available at: $<$ https://www.iea.org/reports/global-ev-outlook2020> Accessed on December 15, 2020.

[9] Tesla Model 3 Had More Sales Than 2nd, 3rd, 4th, 5 th, +6 th Best Selling Electric Vehicles In 1st Half Of 2020 [online]. Available at: $<$ https://cleantechnica.com/2020/08/02/tesla-model3-had-more-sales-than-2nd-3rd-4th-5th-6th-bestselling-plugin-vehicles-in-1st-half-of-2020/> Accessed on December 15, 2020.

[10] YILMAZ, M. - KREIN, P. T.: "Review of benefits and challenges of vehicle-to-grid technology," 2012 IEEE Energy Conversion Congress and Exposition (ECCE), Raleigh, NC, USA, 2012, pp. 3082-3089, doi: 10.1109/ECCE.2012.6342356. Available at: $<$ https://ieeexplore.ieee.org/document/6342356>

[11] BHARGAVI, K. M. - JAYALAKSMI, N. S. MALAGI, S. - JADOUN, V. K.: "Integration of Plugin Electric Vehicles in Smart Grid: A Review," 2020 International Conference on Power Electronics \& IoT Applications in Renewable Energy and its Control (PARC), Mathura, India, 2020, pp. 214-219, doi: 10.1109/PARC49193.2020.236595. Available at: $<$ https://ieeexplore.ieee.org/document/9087208>

[12] MWASILU, F. - JUSTO, J. J. - KIM, E. K. - DO, T. D. - JUNG, J. W.: "Electric vehicles and smart grid interaction: A review on vehicle to grid and renewable energy sources integration", Renewable and Sustainable Energy Reviews, Volume 34, June 2014, Pages 501-516. ISSN 1364-0321. Available at: $<$ https:/www.sciencedirect.com/science/article/abs/p ii/S1364032114001920>

[13] BEN SASSI, F. H. - ALAOUI, C. - ERRAHIMI, F. - ES-SBAI, N.: ,Vehicle-to-grid technology and its suitability for the Moroccan national grid", Journal of Energy Storage, Volume 33, 2021, 102023, ISSN 2352-152X. Available at: $<$ https://www.sciencedirect.com/science/article/pii/S 2352152X20318582>

[14] Vehicle-to-grid technology [online]. Available at: $<$ https://www.whichcar.com.au/car-advice/what-isvehicle-to-grid-charging > Accessed on April 2, 2020.

Received January 4, 2021 , accepted May 31, 2021

\section{BIOGRAPHIES}

Daniel Pál was born in 1994. In 2018 graduated (MSc) at the Department of Electrical Power Engineering on the Faculty of Electric Engineering and Informatics at Technical University in Košice. He received a master's degree in electric power engineering on subject design for the reconstruction of school spaces lighting. At present is a Ph.D. student in the Department of Electrical Power 
Engineering on the Faculty of Electrical Engineering and Informatics at Technical University in Košice. His scientific research is mainly focused on research of renewable resources of energy and for the reduction of the power losses in SMART GRIDS.

Lubomír Beňa was born in 1975 in Bardejov, Slovakia. In 1998 he graduated (MSc) at the Department of Electric Power Engineering, Faculty of Electrical Engineering and Informatics, TU of Košice. He defended his PhD. in the field of overhead power lines mechanics in 2001. Since 2010 he is associated professor at the Department of Electrical Power Engineering. His scientific research is analysis of electrical power systems and optimization problems in electrical power engineering.

Maksym Oliinyk was born in 1994. In 2018 graduated (MSc) at the Department of Electric Power Engineering on the Faculty of Electrical Engineering and Informatics at Technical University in Košice. He received a master's degree in electric power engineering on subject Smart Grid. At present is a Ph.D. student in the Department of Electrical Power Engineering on the Faculty of Electrical Engineering and Informatics at Technical University in Košice. His scientific research is mainly focused on design and researching SMART GRIDS. 